\title{
Do delírio racista à insistência negra em viver: uma análise do olhar psicopatológico brasileiro e o esforço descolonial
}

\author{
From racist delirium to black insistence on living: \\ an analysis of the Brazilian psychopathological view \\ and the decolonial effort
}

\author{
Alexandre Manzoni - \\ Mestrando pelo Programa de \\ Pós-Graduação em Sociologia \\ (PPGS) da Universidade Federal \\ do Rio Grande do Sul na \\ linha de pesquisa Sociedade e \\ Conhecimento \\ xandy.manzoni@gmail.com \\ https://orcid.org/0000-0002- \\ $\underline{4610-0678}$
}

Recebido em: 07/09/2020

Aceito em: 22/03/2021

\section{RESUMO}

O artigo traz reflexões acerca do colonialismo como acontecimento moderno, percorrendo os processos eugênicos de racialização originados na Europa Ocidental. Opera a análise de múltiplas faces do racismo brasileiro, como injúrias voltadas a traços fenotípicos negróides, mobilidade social precária da população negra e aspectos mitológicos da colonização, que regem o cotidiano das relações no Brasil sob o prisma racial. O trabalho se debruça sobre manchetes contemporâneas de grande repercussão, evidenciando a maneira como a racialização se traduz na manutenção de um estatuto colonial racista. Propõe uma chave de leitura do racismo brasileiro nos termos de um olhar psicopatológico. A psicopatologia negrofóbica se dá como produto de uma falsa-projeção sobre os corpos negros, vítimas de um homicídio ontológico e, portanto, cingidos pelo delírio racial. Por fim, sugere algumas formas teóricas e práticas para que possamos pensar outros horizontes junto as margens do social, municiando sublevações anticoloniais e antirracistas, incendiando o desejoso combate minoritário contra o panorama racista brasileiro.

Palavras-chave: Racismo, Colonialismo, Modernidade, Psicopatologia, Descolonialismo.

\section{ABSTRACT}

The article brings reflections about colonialism as a modern event, covering the eugenic processes of racialization originating in Western Europe. It operates the analysis of multiple faces of Brazilian racism, such as injuries aimed at black phenotypic traits, precarious social mobility of the black population, and mythological aspects of colonization, which govern the daily relations in Brazil from a racial perspective. The work focuses on contemporary headlines of great repercussion, evidencing the way in which racialization translates into the maintenance of a racist colonial status. It proposes a key to the reading of Brazilian racism from a psychopathological perspective. Negrophobic psychopathology occurs as a product of a false projection on black bodies, victims of an ontological homicide and, therefore, constrained by racial delirium. Finally, it suggests some theoretical and practical ways so that we can think about other horizons along the margins of the social, providing anti-colonial and anti-racist upheavals, igniting the desirous minority fight against the Brazilian racist scene.

Keywords: Racism, Colonialism, Modernity, Psychopathology, Decolonialism. 


\section{INTRODUÇÃO}

Com o alvorecer da modernidade o mundo ocidental seria marcado pelo modo como se articularam ao menos três forças: o modo de produção capitalista, a Igreja Católica e os Estados nacionais. Orientados por doutrinas político-filosóficas racionalistas e individualistas, os Estados europeus inauguravam a colonização processual de povos considerados primitivos, promulgando o embrião predominante do liberalismo social e econômico que manteria no seu germe o modus operandi colonial. Tanto por contingências, quanto por necessidades, o sistema de pensamento levado a cabo na Europa pelo estopim colonial efabulou uma autoficção narcísica no modo pelo qual o europeu passou a se autoidentificar (MBEMBE, 2014).

A estrutura de alteridade lançada pelo sistema colonial impediria a identificação europeia em relação aos diferentes, não os reconhecendo enquanto indivíduos. $O$ aporte eurocêntrico alicerçou a identificação do europeu em relação a si mesmo, por aquilo que acreditara ter sido em tempos passados (MBEMBE, 2014). Para sustentar a crença, lançaram uma cruzada em direção ao progresso humano. Fosse pela cruz e a espada ou posteriormente pelas ciências e políticas eugênicas, promoveriam condições de autoidentificação reivindicando uma descendência com os gregos antigos (MBEMBE, 2014). Em nome do passado e da descendência parental com filósofos e reis se arraigou no cerne de seu comportamento um senso de virtude que se justificava, nessa perspectiva, pela supremacia biológica caucasiana (FANON, 2008).

A narrativa elaborada pôs a história como linear, suspendendo as rupturas socioculturais e processos de errância humana dos debates hegemônicos sobre os Estados europeus. Esta linearidade, junto da violação de grupos, colonização de povos e promoção de leis arbitrárias, fez com que os homens racionais se arrogassem como a medida universal de humanidade, higienizando as sociedades de suas marcas de desrazão, paganismo, primitivismo e, principalmente, das características biológicas e culturais distintas daquelas observadas no padrão caucasiano e cristão europeu (FOUCAULT, 2005).

Esse movimento se articulou radicalmente, dando espaço a invenção fantasmática do continente africano como o lado sombrio da modernidade e, por conseguinte, das pessoas negras como a infância da história, como a criança que o europeu teria sido no passado, no tempo marcado pelo ponteiro evolucionista da cronologia ocidental (FANON, 2008). Elevaram-se processos de estigmatização, com a fixação de alteridades patológicas, ou melhor, alteridades inumanas aos grupos cuja origem não se baseava nos espíritos embrionados em antigas civilizações ocidentais, desencadeando nas sociedades europeias a leitura dos outros enquanto raças outras (MBEMBE, 2014).

À luz dos fatos e da lucidez sabemos que raça não existe em termos biológicos quando nos referimos a humanos. Entretanto, podemos desconstituir a mitologia de origem dos processos de colonização se inventariamos os elementos que denotam o quanto raça é produzida como acontecimento histórico. Pensamos, portanto, que raça se submete a enfeixes relacionais, espacialidades, momentos socioculturais e político-econômicos.

Raça não é, raça está. Raça não procede como substância, eclode discursivamente com a produção de corpos e corporalidades. Brancura e negrura não se submeteram a classificações epidérmicas coloniais sem que antes houvesse compartimentações do gênero humano em variações ontológicas, que pinçaram nas distintas constituições corporais os gradientes de cor e características fenotípicas que justificavam, do ponto de vista dos colonizadores, a violação de pessoas, comunidades e continentes.

Os processos de racialização são a pedra fundamental da construção do racismo como sistema inseparável da modernidade, considerando que foi pela atribuição de hierarquias fenotípicas que tanto as sociedades colonizadas quanto as sociedades colonizadoras perpetuaram padrões de humanidade em escala global. Mitologicamente, pessoas negras teriam sido desterritorializadas e escravizadas pelo fato de serem negras. Desmistificamos essa narrativa quando a preenchemos de história, e nos deparamos com o fato de que foi pela colonização, com o estabelecimento da vida em cativeiro, da vida acorrentada e escravizada, que a opressão desaguou numa inferiorização epidérmico-racial (MUNANGA, 1988). 
As pessoas negras, ao longo de séculos, pelo tráfico transatlântico, pelas migrações forçadas, estupros em massa, destruição de rituais religiosos, negação de identidades individuais e coletivas, entre outras formas de apagamento étnico, seriam produzidas como cadáver da modernidade (MBEMBE, 2014). Em síntese, vítimas de um assassinato ontológico sem paralelos arvorado pelo mundo ocidental.

Os sistemas simbólicos africanos seriam degradados desde que o primeiro navio negreiro sequestrou habitantes em África. A eliminação física dos corpos negros - classificada de modo exímio na literatura sociológica enquanto genocídio (NASCIMENTO, 2016) -, bem como o saque sobre costumes, práticas e organizações sociais de matriz africana (ANDRÉ, 2007), gerava uma fissura no sistema de vida dos africanos e uma mácula nos processos de subjetivação experimentados pelos afrodescendentes nas colônias, na medida em que a historicidade de um grupo afeta as trajetórias daqueles que dele fazem parte (ANDRÉ, 2007).

No caso do Brasil o exemplo da situação é didático, considerando que o continente africano é comumente entendido como país e muitos afro-brasileiros desconhecem a região exata da África na qual nasceram seus antepassados. Em contrapartida, os euro-brasileiros sabem exatamente da sua descendência, se ela é em relação aos italianos, alemães, poloneses ou espanhóis. Sabem pelo sobrenome, sabem pela encenação de ritos simbólicos e culturais de seus antepassados e, até mesmo, pelo aprendizado da língua do país de descendência no núcleo familiar.

Em vista do exposto, as linhas que seguem pretendem fazer deste artigo um artefato político-epistêmico que intervenha no presente de modo que os fatos decomponham, sob o crivo socioanalítico, as faces do racismo colonial operante no Brasil. Fazendo uso de manchetes contemporâneas de grande repercussão desenhamos um quadro de análise da racialização brasileira ao perguntarmos: de que modo a racialização opera para que os padrões relacionais e a mobilidade no Brasil sejam mantidas sob o estatuto do racismo colonial?

Por fim, contamos com algumas contribuições teóricas e práticas para que possamos pensar outros horizontes junto as margens, ao mesmo tempo que municiamos as sublevações anticoloniais e antirracistas para o combate direto do panorama racista brasileiro.

\section{Breve inventário teórico sobre a historicidade racial}

Ao elaborar formas binárias de percepção do mundo social, o pensamento eurocêntrico defendia que as pretensas raças seriam constituídas por essências incomunicáveis umas em relação as outras. De modo que os processos de colonização supunham que as pessoas teriam naturezas autorrealizáveis, com destinos traçados pelo espírito de cada povo, sendo o espírito humano aquele que se transformava, ocupava papéis, percorria trajetórias e selava o destino de um povo ou da humanidade (MBEMBE, 2014). Sob a égide do narcisismo, o espírito europeu figurava como o responsável por levar a humanidade ao progresso, o que não poderia ser feito sem a cristianização e a civilização dos povos atrasados.

Com o tempo, foi pela tentativa de estabelecer o racismo enquanto ciência que as teorias genéticas originadas no fim do século XVII e início do XVIII se concretizaram em leis persecutórias. Francis Galton defendeu que a raça humana deveria evitar cruzamentos com seres inferiores (GALTON, 1982). Galton analisava as alarmantes diferenças de condições socioculturais entre os países colonizados e os países colonizadores, descrevendo as condições desumanas dos primeiros como parte da natureza dos povos. Abstraindo, para formular a blasfêmia, os cruéis impactos da colonização, da exploração e do genocídio. Esse, no entanto, não era um pensamento individual, mas o pensamento predominante nos estratos burgueses europeus que dariam origem a pseudociência eugênica.

Para produzir o negro, a eugenia recorreu a teses biológicas que descreviam como a cor das pessoas indicava sua essência e, portanto, seus níveis de desenvolvimento (SANTOS, 2002). Do ponto de vista antropológico a eugenia atestava que os diferentes grupos humanos eram naturalmente separados por uma hierarquia racial que refletia numa hierarquia social. A fixação eugênica pelas diferenças fenotípicas resultou 
no estabelecimento de códigos jurídicos que criminalizavam pessoas de determinadas raças (SANTOS, 2002). Mediam-se os crânios, as mãos e o pênis para absolver ou condenar.

Abandonada e abominada com o tempo, a eugenia manteve algumas das suas dimensões no tecido social, como a frequente exotização de grupos minoritários, sobretudo, no caso brasileiro, a exotização da população negra. Esses movimentos eugênicos, junto da influência dos Estados nacionais europeus onde a raça era atributo de virtude e baseava os mitos de fundação das nações, se condensaram num Brasil altamente diverso do ponto de vista étnico-racial como um impedimento para o desenvolvimento nacional (VIANNA, 1952).

Após a abolição da escravatura, o pensamento social brasileiro se debruçou em assimilar a população negra em termos evolutivos, no qual a única solução para civilizar e modernizar a nação seria o estabelecimento de um projeto de branqueamento do país (PAIXÃO, 2005). Na estratégia progressiva, que atravessaria gerações, a população negra seria transmutada num tipo de brasileiro eugênico (FREYRE, 2006). As elites nacionais acreditavam que a miscigenação só poderia branquear, jamais empardecer ou enegrecer a população brasileira, o que só pode ser pensado pela crença na superioridade caucasiana em relação aos caracteres biológicos inferiores de indígenas e afrodescendentes (PAIXÃO, 2005).

Do início ao fim esse processo infame se constituiu como um processo de racialização. Todavia, o resultado foi o oposto do esperado, forçando uma rearticulação ideológica das elites, que promoveram o grande mito de que a mistura racial daria ao Brasil uma indistinção de cor e de raça (FREYRE, 2006). Esse gesto de força resultava no monopólio dos recursos materiais e simbólicos pelos grupos raciais brancos, restando aos negros uma mobilidade social precária e a estigmatização racial (FERNANDES, 1978).

Para o mito da democracia racial, no Brasil não existiria racismo contra negros, tendo em vista que a miscigenação propiciava, desde as bases da família, um antídoto contra violências raciais. Se atentamos para os fatos esse argumento não se realiza, já que os matrimônios inter-raciais não figuram no passado da nação para além de um número ínfimo, sendo a mestiçagem originada sobretudo pelo estupro de mulheres escravizadas pelos senhores de engenho e não de relações conjugais (NASCIMENTO, 2016).

Estratagema que integra a ideologia da mestiçagem se dá na tentativa não declarada de alienar pessoas pardas/não-brancas, tentando impedir que se percebam como racializadas e, na pirâmide social, próximas a pessoas pretas. Posto que isso poderia produzir no sistema de identificação colonial uma dimensão subversiva (GUIMARÃES, 1999).

De acordo com Oracy Nogueira, no Brasil a proporção do preconceito sofrido seria referente aos fenótipos de cada pessoa, destacando-se entre eles: cor da pele, tipo de cabelo, formato do nariz e dos lábios (NOGUEIRA, 1998). Quanto mais negroides forem os traços, maior a possibilidade de que o indivíduo sofra com o racismo. O preconceito de cor contra pessoas negras sintetizaria o preconceito dos traços fenotípicos, denominados por Oracy como preconceito racial de marca (NOGUEIRA, 1998).

Primeiramente com o mito gilbertiano e num segundo momento com uma má apropriação do trabalho de Oracy Nogueira, foi possível a construção da ideia de que os brasileiros miscigenados teriam ingresso garantido no mundo social e institucionalmente branco. O que se constituiu, de fato, como uma maneira daqueles que exerciam o poder de garantir um desejo de brancura por aqueles que sonhavam ser incluídos socialmente ou pretendiam incluir seus herdeiros por procuração (ANDRÉ, 2007).

Na teoria de Carl Degler (1976), os pardos teriam uma válvula de escape racial ao constituírem uma categoria com lugar reservado na sociedade, que não era o mesmo dos brancos, mas estava distante do lugar ocupado por pessoas pretas. Seu argumento apontava para uma diferença substantiva na mobilidade social de pretos e pardos.

Essa teoria seria colocada estatisticamente em xeque por estudos que demonstravam a proximidade de pardos e pretos do ponto de vista socioeconômico (HASENBALG; VALLE E SILVA, 1988). Enquanto pardos e pretos experimentavam condições semelhantes entre si, quando comparados aos grupos brancos eram segregados por uma enorme distância socioeconômica, educacional e de mobilidade (HASENBALG; VALLE E 
SILVA, 1988). Os trabalhos de Valle e Silva e Hasenbalg abriram uma ferida na ideologia do branqueamento, permitindo que os movimentos negros brasileiros tivessem a evidência para atuar no campo político unindo pardos e pretos sob a identidade negra (SILVA; LEÃO, 2012).

Embora a delimitação verbal de cor/raça seja difícil no Brasil, em que pese a proliferação de eufemismos que evitam o termo negro, essa reconstrução histórica nos parece importante. Sobretudo, quando a autoidentificação dos brasileiros negros que possuem vínculos sanguíneos com pessoas brancas indica, de modo recorrente, o quanto está arraigado no país o pensamento colonial e o fetiche da brancura pelo paradoxo da mistura (SILVA; LEÃO, 2012). Na medida em que a palavra negro é substituída frequentemente por moreno, café-com-leite ou jambo, como explicitou o censo produzido por Clóvis Moura (1988) que apresentava 136 cores pelas quais as pessoas se autoidentificaram, seria interessante observar as possíveis formas de branqueamento simbólico da materialidade corporal.

A partir da magistral obra Pele Negra, Máscaras Brancas, Frantz Fanon (2008) nos propõe uma leitura tanto do racismo quanto do colonialismo como formas sociais capazes de obstruir nossas categorias de apreensão do mundo social. Estas formas, operacionalizadas e cristalizadas na vida cotidiana pela linguagem, pelos estatutos epistêmicos, pela constituição psíquica e pela elaboração de esquemas corporais, sedimentariam nossos modos de ver, sentir e viver no mundo.

Pensamos que os corpos não existem fora de uma trama de relações sociais, em que conjuntos de práticas criam determinadas configurações. Num emaranhado histórico complexo como aquele inaugurado pela colonização é que os corpos negros foram saturados de elementos ilusórios. E, com um golpe de força, seriam encerrados em categorias radicalmente distintas daquelas que representavam os corpos brancos. Estas categorias, articuladas as concepções do humano, fizeram com que os diferentes corpos estivessem atrelados a efabulações distintas não apenas do ponto de vista cognitivo, como também afetivo e estético.

O que emerge no olhar branco que inferioriza o corpo negro não é uma imagem do real, mas uma imagem pretensamente verdadeira, que se justifica tão somente pela objetificação do que acredita ver. Uma imagem trabalhada num conjunto específico de formação psicossocial, que não é estabelecido simplesmente pela fixação de um outro, mas pela negação do outro, uma ausência.

Não se trata de uma questão particular, em que as pessoas individualmente promoveriam os próprios preconceitos. Atentamos para o fato de que os sujeitos ao nascerem dentro de um sistema colonial incorporam de modo insensível e irrefletido, desde a socialização familiar, oposições fundamentais que sacralizam afetivamente os modos como os corpos são vistos. A linguagem se constitui como um primeiro imperativo, retórico e ao mesmo tempo prático, para sustentar as relações sociais assimétricas e, portanto, se torna cúmplice imediata nas formas como os olhares são constituídos de maneira racializada.

A imagem que temos de nós está vinculada ao modo como vemos nosso grupo de pertença. Por isso, não é incomum que as ações dos sujeitos visem a proteção das crenças e valores compartilhados pela coletividade na qual se inserem, já que estes elementos estão enraizados em nós, corporificados pelos processos de subjetivação que experimentamos junto as instituições e espaços pelos quais transitamos.

No entanto, o que se materializa numa sociedade racista não é simplesmente a defesa de valores de um ou outro grupo. Em uma sociedade racista essa defesa assume uma dimensão psicopatológica pela fobia do negro, provocando a objetificação da pessoa negra como alteridade radical. Transformando-a numa miragem destituída de atributos positivos e, gradativamente, inferiorizando aqueles que não são brancos pelos seus traços de impureza.

Os processos de exclusão, exploração e desumanização do outro levados adiante por um grupo social dominante é tanto fruto da estigmatização direta, exercida por alguns indivíduos que dele fazem parte, quanto pelo silenciamento e a omissão coletivos diante da brutalização racial que privilegia o grupo como um todo. Trata-se, em resumo, do quanto indivíduos brancos podem se beneficiar em âmbito escolar, profissional e social do seu tom de pele e traços corporais, assimilados esteticamente como desejáveis (nariz afilado, cabelo 
liso, lábios finos etc.). Por isso é que "mesmo em situação de pobreza, o branco tem o privilégio simbólico da brancura" (BENTO, 2002, p. 3).

Os indivíduos brancos, mesmo que pobres, conquanto não sejam acrescidos marcadores marginais e ou condutas desviantes, não são compulsoriamente tomados como suspeitos ou culpados no Brasil. Em contraponto, o fato de uma pessoa negra ocupar um cargo de prestígio ou uma classe social elevada, não a exime das relações assimétricas marcadas pelo racismo. E não são raras as ocasiões em que pessoas negras percebem que são toleradas por um lugar de autoridade que ocupam, pelo status de sua posição, e não respeitadas por seu valor de pessoa.

Antes de ser uma pessoa, o indivíduo depreciado em termos raciais é um adjetivo. A palavra negro é sempre proferida antes de um elogio, insulto ou mesmo um chamamento corriqueiro. As pessoas negras muitas vezes têm a epiderme como nome próprio. Esta trama faz parte do cotidiano colonial, em que o negro é (re)produzido como a negativação do bom e do belo (FANON, 2008). Na situação colonial a diferença ontológica é mobilizada constantemente para tornar o negro incapaz de uma alteridade potente. Isto, nos termos deste trabalho, fala mais sobre o Ocidente e, especialmente sobre o Brasil, do que as narrativas liberais economicistas que forçam uma amnésia da gênese histórica do racismo e do colonialismo.

\section{A psicopatologia, a distinção branca e o supliciamento negro}

Nas páginas que seguem, decompomos alguns episódios presentes na sociedade brasileira articulando os processos de racialização com o estatuto colonial vigente. Atribuímos ao olhar uma dimensão subjacente importante no modo como opera o racismo em nossa sociedade, percebendo que a forma pela qual se vê o corpo negro preserva intactas algumas das características de origem do processo de colonização. Segundo Fanon:

[...] o judeu pode ser ignorado na sua judeitude. Ele não está integralmente naquilo que é. As pessoas avaliam, esperam. Em última instância, são os atos e os comportamentos que decidem [...]. Mas comigo tudo toma um aspecto novo. Nenhuma chance me é oferecida. Sou sobredeterminado pelo exterior. Não sou escravo da "ideia” que os outros fazem de mim, mas da minha aparição (FANON, 2008, p. 108).

Fazemos coro ao excerto, tendo em vista um caso de repercussão nacional ocorrido na cidade de Valinhos, região metropolitana de Campinas, Estado de São Paulo. Trata-se da divulgação de um vídeo em que um jovem entregador de alimentos por aplicativos é agredido verbalmente por um cliente num condomínio de classe média alta (EPTV, 2020). O trabalhador, que independente da sua autoidentificação racial foi lido fenotipicamente como não branco, seria vítima de ofensas racistas. Num espaço de branquitude pequeno burguês o agressor (homem branco), na medida em que ofendia o jovem enaltecia o quanto sua brancura se traduzia num status de nobreza e superioridade moral, cultural, intelectual e humana.

No início da filmagem, o agressor aparece dizendo ao jovem o seguinte: "seu lixo, você tem inveja dessas famílias". Num primeiro momento, o trabalhador assimila (considerando sua reação) a frase como resultado da condição socioeconômica do agressor, no que responde a seu algoz: "eu também posso ter a mesma coisa que o senhor". O agressor então rebate: "você tem inveja disso aqui" - esfregando as mãos sobre o antebraço, indicando ao jovem, num tom de deboche e soberba, que aquele que seria o objeto de sua inveja era a brancura de seu corpo. O detrator encerraria o prólogo mórbido com uma exclamação que faz tremer os nervos, os tendões, as artérias, causando repulsa ao estômago: "você nunca vai ter isso!".

A leitura que fazemos do fato é de que existe uma dimensão narcísica que alimenta a cosmovisão do agressor, capaz de produzir um olhar e uma atitude que só se tornam possíveis pelo fato de que a brancura opera como elemento de distinção numa sociedade racializada como a brasileira. Trata-se de uma justificação 
para uma existência corporificada pela brancura, e acometida por uma neurose fóbica decorrente da estrutura de alteridade colonial, que infla o Ego a tal ponto que se torna necessário proteger a crença, no mais íntimo de seus sentimentos, de que sua condição privilegiada seria obra da supremacia biológica e estética brancas. Digamos, na esteira de Maria Aparecida Bento, que:

\begin{abstract}
Representar o outro como arauto do mal serviu de pretexto para ações racistas em diferentes partes do mundo. A agressividade pôde ser dirigida contra esse inimigo comum (a outra raça), sentida como ameaça, ainda que na maioria dos lugares ela não tivesse nenhum poder. Os sujeitos perdem a capacidade de discernir entre o que é deles e o que é alheio, e então tudo vira falsa-projeção, exterioridade. Sob a pressão do superego, o ego projeta no mundo exterior, como intenções más, os impulsos agressivos que provêm do id e que, por causa de sua força, constituem uma ameaça para ele próprio. Ao projetar os impulsos consegue livrar-se deles e, ao mesmo tempo, reagir a eles, como algo que pertence ao mundo exterior (BENTO, 2002, p. 12-13).
\end{abstract}

O que estava atrofiado no contato entre o trabalhador e o agressor era a própria capacidade do sujeito branco de se identificar com uma pessoa não branca e pobre como diferente e ao mesmo tempo tão humana quanto. Criava-se, deste modo, as bases para hostilidades, violências e brutalidades contra a diferença representada pela figura do corpo não branco que passava a circular num espaço de branquitude.

O olhar branco que localiza o corpo negro na estrutura colonial nada mais é do que um olhar obstruído, perturbado, que tende ao quixotismo. Um olhar de quem vê o que um invólucro de maledicência faz ver. Os conceitos elaborados em torno do corpo negro governam aprioristicamente a apreensão do corpo pelo olhar. Somente por um olhar atrofiado e sádico que a falsa-projeção é capaz de engendrar um ódio narcísico pela diferença, na mesma medida em que possibilita amar narcisicamente a semelhança (BENTO, 2002).

Poderíamos considerar o fato nos termos de uma esclerose afetiva do branco (FANON, 2008), no entanto, parece mais adequado organizarmos o acontecimento sob o prisma da psicopatologia. Na psicopatologia a repulsa é fundamentada por uma alucinação negativa (SOUZA, 1983), desconfiança e medo infundados na realidade, mas vívidos na escala da imaginação. O que eclode em cariz persecutório aos corpos cuja projeção fantasmagórica de monstruosidade justificaria, para o agressor, uma postura de vigilância constante ou violência prévia.

Sendo difícil abstrair o corpo como foco de desconfiança e objeto de violência, se impõem obstáculos cotidianos para que os indivíduos negros vivam seu corpo, amem seu corpo, sintam seu corpo (SOUZA, 1983). Um corpo que não consegue ser visto como mais um corpo dentre os corpos, um corpo perseguido, malquisto, alvo constante de morte e suplício.

O que é que isso significava para mim, senão um desalojamento, uma extirpação, uma hemorragia que coagulava sangue negro sobre todo o meu corpo? No entanto, eu não queria esta reconsideração, esta esquematização. Queria simplesmente ser um homem entre outros homens (FANON, 2008, p. 106).

A formação do Ego tem origem na acomodação das experiências, que envolvem dimensões representativas, emocionais, imagéticas e nominativas (SOUZA, 1983). O papel ideal do Ego se refere ao modo como a subjetividade se produz na inserção da criança pelos adultos no universo sociocultural e, ao mesmo tempo, como seu corpo incorpora afetiva e eroticamente os outros (SOUZA, 1983). No caso de um país colonizado como o Brasil a formação psicossocial pode figurar na branquitude na forma de um refluxo narcísico que exorciza seus outros como possíveis ameaças.

Sendo o jovem entregador de Valinhos uma pessoa não branca que foi identificada como tal, não seria imprudente dizer, considerando seu fenótipo, que dificilmente seria considerado sociológica ou socialmente 
como uma pessoa preta. O que mostra a falsidade da cantiga colonial que afirma o quanto pessoas pardas seriam inclusas socialmente, diferente das pessoas pretas. A partir disso, explicitamos que aquilo que de fato existe no arranjo colonial brasileiro é uma ideologia das corporalidades, o repúdio fenotípico se dá como repúdio corporal. A mitologia se instala por meio da estereotipação estética de pessoas não brancas, com a degradação sistemática das características negroides pela adjetivação depreciativa.

$\mathrm{Na}$ boca do racista os lábios negros se transformam em beiço grosso, seu nariz é um nariz de batata, seu cabelo é cabelo ruim, sua bunda é bunda de saúva. O que o negro faz só poderia ser coisa de negro, sua fome é fome de negro, seu sexo é sexo de negro, seu cheiro é cheiro de negro, não de pessoa, não de gente, de negro. Antes de ser João, José ou Maria, se é o negro/a negra, restando ao nome próprio o lugar de sobrenome.

Embora o pardo seja lido como branco em determinadas ocasiões, e toda a mitologia nacional tente introjetar nessas pessoas o quanto elas podem se tornar quase brancas com o apagamento de seus traços, seja pelo comportamento, pelas vestimentas ou procedimentos estéticos, os pardos no Brasil são no mínimo suspeitos quando não os culpados, de um crime cuja materialidade se faz pela própria existência enquanto tal. Há, inclusive, manifestações públicas especificando o quanto estas pessoas dever ser vítimas de abominação pelo seu mau-caráter (PEREZ, 2019).

Seria interessante observar as distintas formas de classificação e autoclassificação localizadas geograficamente no Brasil e o quanto isso se vincula a colonialidade (GUERREIRO RAMOS, 1995). Salientamos que há pesquisas realizadas no Brasil onde os resultados apontam que a autoidentificação de pessoas como pardas depende da pigmentação da pele, da indicação de cor/raça em certidão de nascimento ou ser filho de uma pessoa branca, o que faz com que se distanciem da negritude nas narrativas sobre si (SILVA; LEÃO, 2012). Em contrapartida, as pessoas pardas que vinculam sua identificação como negras manifestam a consciência de que já sofreram discriminação em algum momento relacionada a seus traços fenotípicos (SILVA; LEÃO, 2012).

Dupla violência da ideologia do branqueamento, de um lado tenta estimular a negação da negritude por pessoas pardas, chantageando com aceitabilidade pelo que possuem de brancura; por outro lado, se mantém o olhar racializante sobre esses corpos miscigenados. Independente das inúmeras nomenclaturas socioantropológicas atribuídas, como pardo, negro de pele clara, não branco, esses corpos se tornam violáveis numa sociedade fundamentada pelo colonialismo. Podemos deixar uma pergunta em aberto a ser respondida por trabalhos socioantropológicos futuros e pela psicologia social: que implicações psíquicas observamos em pessoas pardas quando incorporam a ideologia do branqueamento e exercem sobre si uma metamorfose corporal que requer a negação daquilo que são integralmente?

Por conseguinte, vemos que o impasse do não lugar dos negros de pele clara, de fato, não é um impasse, não apenas pelas estatísticas socioeconômicas, mas pelo tratamento cotidiano. A taxonomia colonial que enquadra humanos em índices de brancura produz seus feitiços, seus truques de ilusão, mas ao fim e ao cabo os negros, ainda que miscigenados, e independente da autoidentificação e da turvação ideológica serão lidos, ao menos por racistas, como corpos enegrecidos. Pois, na sociedade brasileira a verdadeira brancura representa um elemento de distinção a ser conservado de modo belicoso.

Prevenindo nosso argumento de possíveis mal-entendidos, não se trata de equiparar o quantum de racismo sofrem pessoas pardas quando comparadas a pessoas pretas. Principalmente se consideramos que para as pessoas pretas a epidermização racista é inescapável, enquanto para os pardos de pele mais clara outras situações podem ser desencadeadas. Porém, nosso esforço está interessado em apontar o quanto os pardos, mesmo que filhos de um branco, e ainda que vejam seus corpos de maneira fantasiada, no limite, esbarram no gradualismo eugenista, em que os traços estéticos caucasianos não se confundem com os traços daqueles que possuem fenótipos negroides ou indígenas.

No quadro analítico bourdieusiano a modernidade é regida por uma dinâmica em que os indivíduos sobretudo nas sociedades com uma massa pequeno burguesa - são orientados por um princípio de existência que é a distinção. Na lógica da distinção, para existir é preciso se distinguir, encarnando em si um ponto de singularização, se tornando aquilo que o outro não é (BOURDIEU, 2007). Traindo Bourdieu ao reorganizar- 
mos sua sociologia para discutir questões raciais, observamos que no Brasil as dimensões estéticas e não a origem de sangue orientam o racismo (NOGUEIRA, 1998). Contudo, os insultos aos que são quase brancos são desferidos nas formas de branco sujo ou encardido, acentuando o quanto os verdadeiros brancos tentam se distanciar socialmente dos que não são realmente brancos.

Se traçarmos uma sociogênese de como opera a lógica da distinção em termos raciais, veremos que os processos eugênicos correspondem a uma forma particular de consagração simbólica e estética brancas. Podemos, inclusive, presentificar essas formas eugênicas de distinção social. Basta pinçarmos a postura dos estratos brancos de classe média e alta no Brasil do século XXI acerca da inseminação artificial. Mesmo desatentos das implicações, esses grupos têm aumentado a importação de esperma estrangeiro (BBC, 2019), na imensa maioria dos casos tendo preferência por traços genéticos euro-estadunidenses (cabelos loiros, olhos azuis, pele branca).

Nesse cenário, a racialização aponta o quanto são indesejados os traços fenotípicos negroides (BICUDO, 2010). Pela inculcação violenta, intermediada pela socialização, pela propaganda, pela escola, é que pessoas negras são inconscientemente estimuladas a enxergar a si, outras pessoas negras, e pessoas brancas, mediante o olhar branco. Pois, a branquidade se impõe ao negro pelas tentativas de deturpação da própria existência, basta observar "que aquilo que se chama de alma negra é frequentemente uma construção do branco" (FANON, 2008, p. 30).

Retomando Valinhos, além do que está documentado na filmagem, o jovem trabalhador revelou que em determinado momento foi cuspido pelo agressor que, simultaneamente, jogava a nota fiscal do restaurante no entregador dizendo: "olha, está vendo? Você é lixo, tem que pegar, você é igual a esse papel". Poderíamos atribuir a esse comportamento um sinal de má índole, falta de caráter, ou quaisquer que fossem as alegações repreensivas em termos individualizantes.

Entretanto, acreditamos que o movimento que individualiza, ao mesmo tempo que toma como desvio de caráter ações desse tipo, se faz nos termos da naturalização colonial a qual nos opomos. Por isso, mobilizamos a psicopatologia vinculada a uma formação psicossocial colonizada e traçamos atitudes que reverberam nojo como disposição incorporada (ELIAS, 2011). Na mesma linha de uma sociologia das disposições, suspeitamos que os indivíduos brancos brasileiros dos estratos médios até a alta burguesia aprendem a humilhar os subalternizados como parte da sua socialização (SOUZA, 2018).

No andamento do vídeo, o agressor ainda atribuiria sua suposta superioridade pelo fato de possuir um nome bíblico, ironizando e acusando de mentiroso o entregador que dizia ter, da mesma forma que o algoz, o nome de um apóstolo. Como indica Fanon, é como se o mundo branco fosse o mundo honesto, e este mundo faz suas exigências quando "os olhares brancos, os únicos verdadeiros, me dissecam. Estou fixado. Tendo ajustado o microscópio, eles realizam, objetivamente, cortes na minha realidade" (FANON, 2008, p. 108). São estes olhares que desejam honestamente do negro uma conduta que dê fé naquilo que o racista pretende ver, afinal, “o branco está fechado na sua brancura. O negro na sua negrura” (FANON, 2008, p. 27).

Os corpos negros são rotineiramente atravessados por olhares de desconfiança, olhares que acima de tudo foram produzindo historicamente os sujeitos negros como objetos ao minar sua autoridade simbólica e intelectual.

Na simbólica não se diz a Justiça Branca, a Verdade Branca, a Virgem Branca? Conhecemos um antilhano que, falando de um outro dizia: "Seu corpo é negro, sua língua é negra, sua alma também deve ser negra". O negro é o símbolo do Mal e o do Feio. Cotidianamente, o branco coloca em ação esta lógica (FANON, 2008, p. 154).

Exemplificando o quanto é cruel o estado das relações raciais brasileiras, vemos a necessidade de escolha por parte das pessoas negras entre a resignação ou o estereótipo de raivosas (em caso de reação), quando interpeladas por uma piada sobre negros vinda de uma pessoa branca. Uma brincadeira, que nada mais é do 
que racismo. Situações em que pessoas negras, além de tudo, ouvem coisas do tipo: "escuta! Eu faço piadas sobre mulheres, faço piadas sobre judeus, e faço piadas sobre gays. E não sou machista, antissemita e muito menos homofóbico, portanto, não me chame de racista. Você não sabe brincar?". Estas são as precisões em jogo.

Quando o trabalhador de Valinhos alertou que chamaria a polícia a frase do agressor foi sintomática: “aqui não vai acontecer nada!”. E, de acordo com o jovem, após estarem na delegacia diante de autoridades os insultos prosseguiram sem maiores danos ao agressor. Refluxo narcísico e privilégio, estas instâncias mostram aos indivíduos brancos brasileiros, sobretudo das classes abastadas, o quanto nossa sociedade é permissiva com seus atos.

Em relação a pessoas negras e pobres quase tudo pode ser feito. Pode-se adultizar crianças negras, transformando em política de Estado a higienização epidérmica de um território e, logo após, fazer do genocídio negro uma notícia (SANTOS; SOARES, 2019). De acordo com Guerreiro Ramos (1995), processos de inferiorização costumam acontecer quando um grupo social é colocado em evidência na forma de assunto. Exemplo disso foi o modo como o sistema nazista transformou os judeus em alvo estampando-os em cartazes.

A junção dos aspectos subjetivos das relações raciais com os elementos objetivos faz com que o racismo seja, simplesmente, um sistema de aniquilação corporal. Para que não sejamos interpretados como vitimistas, exagerados ou alarmistas, precisamos analisar, para além de números, as formas pelas quais o corpo negro se torna alvo de extermínio no Brasil.

Pelas mãos da polícia, um corpo pardo, mesmo que de uma pessoa esquizofrênica, pode ser chicoteado com pedaços de fio (VIANNA, 2019). Uma mãe pode ver seu filho sendo morto por sufocamento pelo segurança do supermercado sem que absolutamente ninguém intervenha $(G 1,2019)$. Um adolescente pode ter seu corpo despido pelos seguranças, ser levado a um porão, e receber chibatadas (LARA; BRIONE, 2019). Num bairro abastado, um jovem negro pode ser amarrado e açoitado junto de um poste, ser exposto nu nas redes sociais como obra de arte e na manhã seguinte ser comentado no jornal de modo obsceno pela branquitude de classe média que ali reside $(\mathrm{G} 1,2014)$. Esse é um país no qual um suspeito negro pode ser assassinado com crueldade num linchamento a céu aberto (FÓRUM, 2015).

Ora, alguém teria a audácia de dizer que estas formas pelas quais se procede contra o corpo negro são violências como quaisquer outras? Ou que se pode exagerar os fatos ao enunciá-los? Em nossa interpretação, todos esses atos hediondos representam a permanência do colonialismo escravagista no Brasil. Primeiro porque são sistemáticos, e segundo porque imageticamente esses episódios fúnebres apresentam não um retorno ou simbolização do escravizado açoitado no tronco pelo feitor, mas mostram cabalmente a contínua monumentalização do corpo negro supliciado. Não esqueçamos, "como explicou Gilles Deleuze, 'há sempre um negro, um judeu, um chinês, um mongol, um ariano no delírio, pois aquilo que faz fermentar o delírio são, entre outras coisas, as raças" (MBEMBE, 2014, p. 11).

\section{Algumas proposições descoloniais}

Estando em jogo no horizonte colonial uma disputa ontológica, cabe ao esforço descolonial a profanação do divino ocidental. Fazer das estátuas de bronze e das catedrais uma fogueira para aquecer os corpos enegrecidos deixados para morrer nas noites frias de inverno. Experimentamos outra matriz de subjetivação, outros encontros, outras artes de viver quando deformamos o pensamento predominantemente colonial.

Do ponto de vista intelectual, precisamos estar atentos sobre o quanto a produção acadêmica compactua com o colonialismo. Basta observarmos as narrativas hegemônicas, consagradas como clássicas, que ainda hoje são reproduzidas no campo científico de modo condescendente e até mesmo acrítico. Não falamos apenas da mitologia que harmoniza nossa guerra racial, também atiramos contra as narrativas que projetam no Brasil uma corrupção endêmica e inata, que supostamente seria o principal problema nacional. Esse estojo teórico, para além do universo acadêmico, conseguiu ser transplantado para o imaginário social. 
Ora, essa mixórdia só pode continuar reverberando no pensamento daqueles que não olham através da janela. Só pode ser escrita pelas mãos dos ensaístas de gabinete. Só pode sair das bocas que pretendem encobrir com verbetes o fato de que no Brasil existe um enigma acerca das minorias raciais: a população negra sendo maioria em termos demográficos segue como minoria nos quesitos sociais, políticos, culturais etc.

Quais são os termos da luta descolonial quando não estamos encastelados academicamente? Para o nosso infortúnio, a indústria acadêmica brasileira mantém certos objetos no altar intocado do prestígio, como o rigor teórico, a coerência intelectual, o Qualis, o Lattes.

Nosso movimento deve estar, senão em desacordo com os moldes acadêmicos, minimamente articulado com aqueles cujo sofrimento do dia a dia produz a empiria. Num Brasil contornado pelo neofascismo, os capitalistas do Lattes continuam acreditando que a ciência vale por si mesma. Não foi suficiente a reação das camadas brancas de classe média em relação as políticas afirmativas para escancarar o quanto as universidades são um meio de manutenção dos privilégios da branquitude?

Destarte, a mudança no perfil da produção científica causada pelos estudantes cotistas com o olhar de estrangeiros tem sido vital na reformulação dos estatutos epistêmicos pela implosão dos paradigmas dominantes. O que a literatura dominante sobre o problema negro escondeu por muito tempo foi o fato de que produção acadêmica também é um ato de guerra.

Por que deveríamos pacificar os processos de resistência negra? Por que não entrar de modo radical no conflito racial por todos os meios possíveis? Por que não escolher a trincheira ao invés da falsa harmonia? Por que permitir que o corpo negro seja sangrado para não ferir o substrato ontológico branco?

Nosso deslocamento analítico deve expor o conflito, a violência, a morte. As confabulações e tramoias dos carrascos coloniais sobre os corpos não brancos. Impulsionar ações inusitadas, impedindo enquadramentos, reduções sociológicas, empobrecimentos da realidade negra, vindos de pesquisas desinteressadas na vida, contanto que sejam imparciais e neutras axiologicamente.

Não podemos, como sugerem alguns, ceder à justiça como máxime ou crer na ficção de um humanismo genérico para desconstituir o estatuto colonial. Para nós, cabe fortalecer a autoridade intelectual e simbólica de formas de vida minoritárias: quilombos, comunidades negras rurais, favelas, periferias etc. Territorialidades que certamente pensam com tanta ou mais sofisticação sobre o racismo na perspectiva do vivido que os doutos da república ao asseverar, pela sagrada concepção, um racismo castiço.

Para o preto que trabalha nas plantações de cana em Robert só há uma solução, a luta. E essa luta, ele a empreenderá e a conduzirá não após uma análise marxista ou idealista, mas porque, simplesmente, ele só poderá conceber sua existência através de um combate contra a exploração, a miséria e a fome (FANON, 2008, p. 185-186).

E, fazendo do pensamento fanoniano uma plataforma de combate, dizemos que diferentemente das lâminas que dilaceram o corpo negro e exercem sobre ele uma dolorosa hemorragia pela epidermização do racismo colonial, a navalha fanoniana é aquela que nos permite operar as retinas obstaculizadas. Cortar a carne ocular não porque sejamos totalmente obturados, não se trata tão somente de vermos ou não: se trata de como vemos.

A potencialidade fanoniana está naquilo que nos faz desconstituir os olhares que veem negros e brancos enquanto corpos dotados de substancialidade, em que uma estrutura de alteridade, dicotomicamente racializada, faz ver o negro como radicalmente distinto do branco, na condição de inumano.

Alertando para as armadilhas da fixação identitária, o pensamento fanoniano oferece a fertilidade dos devires. Os devires das identidades e dos corpos (des)substancializados. O negro não existe como substância, tampouco o branco. Uma consideração elaborada à décadas por Fanon, que poderia nos redimir da estupidez, do delírio, das taras. Uma força pujante para nossa reinvenção como animais humanos a ser decantada numa alquimia de sublimação desracializante e, por excelência, radicalmente descolonial. 


\section{Conclusão}

Por fim, apontamos algumas breves considerações sobre a racialização como meio para a manutenção do racismo colonial. Basicamente, a racialização opera pela produção de significações imaginárias, levando o corpo negro como epicentro de um conflito racial. A fantasia colonialista acaba produzindo uma associação predatória do Ego em relação ao mundo, transformando o desejo numa fonte de violência.

O fato de a sociedade brasileira não ser segregada juridicamente por castas ou por um apartheid oficial, acaba dificultando o reconhecimento das dimensões estruturais do racismo - estruturais na medida em que perpetuam padrões de sociabilidade, relações, crenças, mobilidade etc. Sendo assim, a racialização ao produzir o diferente pelas diferenças fenotípicas permite que no Brasil se opere o prisma colonial sob um olhar psicopatológico, em que a brancura se constitui como elemento de diferenciação social e a negrura como objeto de suplicio.

\section{Referências}

ANDRÉ, Maria da Consolação. Processos de subjetivação em afro-brasileiros: anotações para um estudo. Psic.: Teor. e Pesq. Brasília, v. 23, n. 2, p. 159-167, jun. 2007.

BBC. Importação de esperma: por que a busca por sêmen no exterior cresceu vertiginosamente no Brasil. G1, São Paulo, 9 de fev. de 2019. <https://g1.globo.com/ciencia-e-saude/noticia/2019/02/09/importacao-de-esperma-por-que-a-busca-por-semen-no-exterior-cresceu-vertiginosamente-no-brasil.ghtml>. Acesso em: 7 de set. de 2020.

BENTO, Maria Aparecida. Branqueamento e branquitude no Brasil. In: CARONE, Iray; BENTO, Maria Aparecida (Orgs.). Psicologia social do racismo - estudos sobre branquitude e branqueamento no Brasil. Petrópolis: Vozes, 2002, p. 25-58.

BICUDO, Virgínia Leone. Atitudes raciais de pretos e mulatos em São Paulo. São Paulo: Editora sociologia e política, 2010.

BOURDIEU, Pierre. A distinção: crítica social do julgamento. Porto Alegre: Zouk, 2007.

DEGLER, Carl. Nem preto nem branco: escravidão e relações raciais no Brasil e nos Estados Unidos. WROBEL, Fanny. (Trad.). Rio de Janeiro: Editorial Labor do Brasil, 1976.

ELIAS, Norbert. O processo civilizador. vol. 1. Rio de Janeiro: Jorge Zahar, 2011.

EPTV. TV Globo. Entregador sofre ofensas racistas em condomínio de Valinhos; Vídeo. G1, São Paulo, 7 de ago. de 2020. Disponível em: <https://g1.globo.com/sp/campinas-regiao/noticia/2020/08/07/entregador-registra-boletim-de-ocorrencia-apos-sofrer-ofensas-racistas-em-condominio-de-valinhos-video.ghtml >. Acesso em: 7 de set. de 2020.

FANON, Frantz. Pele negra, máscaras brancas. Salvador: EDUFBA, 2008.

FERNANDES, Florestan. A integração do negro na sociedade de classes. vol. 2. São Paulo: Ática, 1978.

FÓRUM. Revista Fórum. Suspeito de assalto é amarrado a poste e espancado até a morte no Maranhão. Revista Fórum, Santos, 7 de jul. de 2015. Disponível em: $<$ https://revistaforum.com.br/noticias/suspeito-de-assalto-e-amarrado-a-poste-e-espancado-ate-a-morte-no-maranhao/>. Acesso em: 7 de set. de 2020.

FOUCAULT, Michel. Em defesa da sociedade. São Paulo: Martins Fontes, 2005.

FREYRE, Gilberto. Casa-Grande \& Senzala: formação da família brasileira sob o regime de economia patriarcal. São Paulo: Global, 2006.

G1 RIO. TV Globo. Adolescente é espancado e preso nu a poste no Flamengo, no Rio. G1, Rio de Janeiro, 3 de fev. de 2014. Disponível em: <http://g1.globo.com/rio-de-janeiro/noticia/2014/02/adolescente-e-espancado-e-preso-nu-poste-no-flamengo-no-rio.html $>$. Acesso em: 7 de set. de 2020.

G1 RIO. TV Globo. Jovem morre após "gravata” de segurança em mercado na Barra. G1, São Paulo, 14 de fev. de 2019. Disponível em: <https://g1.globo.com/rj/rio-de-janeiro/noticia/2019/02/14/jovem-e-levado-desacordado-a-hospital-apos-gravata-de-seguranca-em-hipermercado-na-barra-rio.ghtml>. Acesso em: 7 de set. de 2020.

GALTON, F. Hereditary genius. London/New York: Macmillan \& Co., 1892. 
GUERRREIRO RAMOS, Alberto. Introdução crítica à sociologia brasileira. Rio de Janeiro: Editora UFRJ, 1995.

GUIMARÃES, A.S. Racismo e anti-racismo no Brasil. São Paulo: Editora 34, 1999.

HASENBALG, Carlos; VALLE E SILVA, Nelson. Estrutura social, mobilidade e raça. Rio de Janeiro: IUPERJ, 1988.

LARA, Walace; BRIONE, Ariane. Adolescente que aparece em vídeo sendo torturado relata que foi chicoteado com fios elétricos em SP. G1, São Paulo, 2 de set. de 2019. Disponível em: <https://g1.globo.com/sp/sao-paulo/noticia/2019/09/02/adolescente-que-aparece-em-video-sendo-torturado-relata-que-foi-chicoteado-com-fios-eletricos-em-sp.ghtml>. Acesso em: 7 de set. de 2020.

MBEMBE, A. Crítica da razão negra. Lisboa: Antígona, 2014.

MOURA, Clóvis. Sociologia do negro brasileiro. São Paulo: Ática, 1988.

MUNANGA, K. Negritude: usos e sentidos. Série Princípios. São Paulo: Ática, 1988.

NASCIMENTO, Abdias. O genocídio do negro brasileiro: processo de um racismo mascarado. São Paulo: Perspectiva, 2016.

NOGUEIRA, Oracy. Preconceito de marca: as relações raciais em Itapetininga. São Paulo: Edusp, 1998.

PAIXÃO, Marcelo. Antropofagia e racismo: uma crítica ao modelo brasileiro de relações raciais. In: RAMOS, Silvia; MUSUMECI, Leonarda (orgs.). Elemento suspeito: abordagem policial e discriminação na cidade do Rio de Janeiro. Rio de Janeiro: Civilização Brasileira, 2005. p. 283-322.

PEREZ, Nathalia. Secretário diz que ‘pardos e mulatos brasileiros são todos mau-caráter' e causa revolta. G1, São Paulo, 18 de abr. de 2019. Disponível em: <https://g1.globo.com/sp/santos-regiao/noticia/2019/04/18/secretario-diz-que-mulatos-sao-mau-carater-e-causa-revolta-na-web-ouca.ghtml>. Acesso em: 07 de set. de 2020.

SANTOS, G. A. A invenção do ser negro: um percurso das idéias que naturalizaram a inferioridade do negro. São Paulo: EDUC/FAPESP, 2002.

SANTOS, Guilherme; SOARES, Paulo Renato. Em 10 meses, Rio tem 6 crianças mortas por bala perdida e poucas respostas para as famílias. G1, Rio de Janeiro, 13 de nov. de 2019. Disponível em: <https://g1.globo.com/rj/rio-de-janeiro/noticia/2019/11/13/em-10-meses-rio-tem-6-criancas-mortas-por-bala-perdida-e-poucas-respostas-para-as-familias.ghtml>. Acesso em: 7 de set. de 2020.

SILVA, Graziella Moraes; LEAO, Luciana T. de Souza. O paradoxo da mistura: identidades, desigualdades e percepção de discriminação entre brasileiros pardos. Rev. bras. Ci. Soc., São Paulo, v. 27, n. 80, out. 2012, p. 117-133.

SOUZA, Jessé. A classe média no espelho: sua história, seus sonhos e ilusões, sua realidade. Rio de Janeiro: Estação Brasil, 2018.

SOUZA, Neusa Santos. Tornar-se negro: as vicissitudes da identidade do negro brasileiro em ascensão social. Rio de Janeiro: Graal, 1983.

VIANNA, Luiz Fernando. Jovem chicoteado pela PM não é caso isolado, mas retrato da história do país. Revista Época, Rio de Janeiro, 4 de ago. de 2019. Disponível em: <https://epoca.globo.com/brasil/jovem-chicoteado-pela-pm-nao-caso-isolado-mas-retrato-da-historia-do-pais-23853972>. Acesso em: 7 de set. de 2020.

VIANNA, Oliveira. Populações meridionais do Brasil. História - Organização - Psicologia. Populações rurais do Centro-sul. Paulistas - fluminenses - mineiros. 5a ed. Rio de Janeiro: José Olympio, 1952. 